\title{
Analyses on Low Cycle Resonance of Ships in Irregular Astern Seas
}

\author{
by Masami Hamamoto*, Member Wataru Sera**, Student Member \\ James P. Panjaitan**, Student Member
}

\begin{abstract}
Summary
In order to investigate capsizing caused by low cycle resonance of ships running in irregular astern seas, an analytical approach has been conducted for computing the fluctuation of metacentric height in irregular astern seas and the power spectrum of metacentric height has been obtained from the time histories of it. The unstable regions of low cycle resonance have been discussed for a container ship and a purse seiner on the basis of Mathieu's equation.
\end{abstract}

\section{Introduction}

When a ship is running in severe astern seas, unstable rolling occurs if the natural rolling period $T$ is close to the specific encounter period $T_{e}$. The specific encounter period of ship running in regular astern seas is obtained as the solutions of Mathieu's equation. Unstable rolling occurs at $T_{e} / T=1 / 2,1,3 / 2, \cdots$. The considerably important unstable rolling is the first resonance at $T_{e} / T$ $=1 / 2$ which is the so called low cycle resonance. This unstable rolling has been investigated theoretically and experimentally by Grim ${ }^{1)}$, Kerwin ${ }^{2)}$, and Paulling ${ }^{3)}$. The low cycle resonance appears to occur in approximately the following sequence. The ship model running in irregular astern seas encounters a group of especially steep waves. When the crest of a wave is about amidships, the stability of the model is drastically decreased and it takes a large roll. This wave moves on past the model and a trough comes into the amidships position while the model is heeled over, resulting in sharply increased stability. This causes the model to come back upright again. This process continues until either the model capsizes or it moves out of the wave group and the motion dies down. The low cycle resonance has been already investigated for a ship in regular seas but not for a ship in irregular seas. The encounter period of ship to waves is important for the occurance of low cycle resonance. The problem is to evaluate the encounter frequency of ship in irregular seas. Takaishi ${ }^{4)}$ has theoretically and experimentally investigated the encounter frequency of the ship running in irregular

\footnotetext{
* Osaka University

** Graduate School, Osaka University
}

Received 10 th July 1995

Read at the Autumn meeting 16, 17 th Nov. 1995 seas by transforming the power spectrum of irregular waves into the power spectrum of encounter frequency of ship running in irregular astern seas without taking into account the fluctuation of metacentric height. The purpose of this paper is to investigate the capsizing by the so called low cycle resonance of a ship running in irregular astern seas. For this purpose, it is discussed in this paper to evaluate the fluctuation of metacentric height as a random process and to derive the equation of motion describing the low cycle resonance in random seas. Finally, numerical examples about the fluctuation of metacentric height and the stable and unstable regions of low cycle resonance have been computed for a container ship and a purse seiner running in irregular astern seas.

\section{The Fluctuation of Metacentric Height GM}

The irregular waves are given by the sum of sinusoidal waves in the space fixed coordinate system $O$ $-\xi, \eta, \zeta$ where the $\xi, \eta$-plane is the equilibrium water surface and the $\zeta$-axis is directed downward. The wave profile $\zeta_{w}$ propagating in the direction of $\xi$-axis is given by

$$
\zeta_{w}=\sum_{n=1}^{N} C_{n} \cos \left[\frac{\omega_{n}^{2}}{g} \xi-\omega_{n} t+\varepsilon_{n}\right]
$$

where $N$ is the number of components wave, $\omega_{n}$ the circular frequency, $\varepsilon_{n}$ random phase angle, $g$ the gravitational acceleration, $t$ time, and $C_{n}$ the amplitude of the $n$-th wave given by the ITTC spectrum (1978),

$$
\begin{aligned}
& C_{n}=\sqrt{2 S_{w}\left(\omega_{n}\right) \Delta \omega} \\
& S_{w}(\omega)=\frac{172.75}{\omega^{5}}\left(\frac{H_{1 / 3}^{2}}{T_{01}^{4}}\right) \exp \left[-\frac{691}{\omega^{4} T_{01}^{4}}\right]
\end{aligned}
$$

Then the velocity potential $\phi$ for this wave profile is given by

$$
\phi=-\sum_{n=1}^{N} C_{n} \frac{g}{\omega_{n}} \exp \left[-\frac{\omega_{n}^{2}}{g} \zeta\right] \sin \left[\frac{\omega_{n}^{2}}{g} \xi-\omega_{n} t+\varepsilon_{n}\right]
$$

Thus the wave pressure $p$ is 


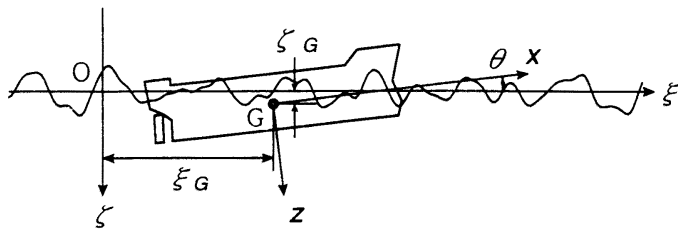

Fig. 1 Space fixed coordinate and ship coordinate systems

$$
\begin{aligned}
p= & \rho g \zeta-\rho g \sum_{n=1}^{N} C_{n} \exp \left[-\frac{\omega_{n}^{2}}{g} \zeta\right] \\
& \times \cos \left[\frac{\omega_{n}^{2}}{g} \xi-\omega_{n} t+\varepsilon_{n}\right]
\end{aligned}
$$

The Froude-Krylov forces and moments may be obtained by integrating the pressure over the entire wetted surface of the ship. In order to evaluate the component of the force and moment in the ship coordinate system $G-x, y, z$, it is necessary to transform the wave profile $\zeta_{w}$ and pressure $p$ in the space fixed coordinate system into that in the ship coordinate system. Assuming here the position of ship at the instantaneous time $t$ to be the $\xi_{G}, \zeta_{G}$ and the trim angle $\theta$ in the space fixed coordinate system as shown in Fig. 1, the $\xi$ and $\zeta$ are approximately equal to

$$
\begin{aligned}
& \xi=\xi_{G}+x \cos \theta+z \sin \theta \simeq \xi_{G}+x \\
& \zeta=\zeta_{G}+z \cos \theta-x \sin \theta \simeq z+\zeta_{G}-x \theta
\end{aligned}
$$

and the $\xi_{G}$ is specified by the ship speed $U$ and initial position $\xi_{0}$ at the time $t=0$ as

$$
\xi_{G}=\xi_{0}+U t
$$

Thus the wave profile $\zeta_{w}$ and pressure $p$ are rewritten as

$$
\begin{aligned}
\zeta_{w}= & \sum_{n=1}^{N} C_{n} \cos \left[\frac{\omega_{n}^{2}}{g}\left(\xi_{0}+x\right)\right. \\
& \left.-\left(\omega_{n}-\frac{\omega_{n}^{2}}{g} U\right) t+\varepsilon_{n}\right] \\
p= & \rho g\left(z+\zeta_{G}-x \theta\right)-\rho g \sum_{n=1}^{N} C_{n} \\
& \times \exp \left[-\frac{\omega_{n}^{2}}{g}\left(z+\zeta_{G}-x \theta\right)\right] \\
& \times \cos \left[\frac{\omega_{n}^{2}}{g}\left(\xi_{0}+x\right)-\left(\omega_{n}-\frac{\omega_{n}^{2}}{g} U\right) t+\varepsilon_{n}\right]
\end{aligned}
$$

and then the pressure gradient in the direction of $z$-axis is

$$
\begin{aligned}
\frac{\partial p}{\partial z}= & \rho g\left\{1+\sum_{n=1}^{N} C_{n} \frac{\omega_{n}^{2}}{g} \exp \left[-\frac{\omega_{n}^{2}}{g}\left(z+\zeta_{G}-x \theta\right)\right]\right. \\
& \left.\times \cos \left[\frac{\omega_{n}^{2}}{g}\left(\xi_{0}+x\right)-\left(\omega_{n}-\frac{\omega_{n}^{2}}{g} U\right) t+\varepsilon_{n}\right]\right\} \\
\simeq & \rho g\left\{1+\sum_{n=1}^{N} C_{n} \frac{\omega_{n}^{2}}{g} \exp \left[-\frac{\omega_{n}^{2}}{g} d(x)\right]\right. \\
& \left.\times \cos \left[\frac{\omega_{n}^{2}}{g}\left(\xi_{0}+x\right)-\left(\omega_{n}-\frac{\omega_{n}^{2}}{g} U\right) t+\varepsilon_{n}\right]\right\}
\end{aligned}
$$

where the $d(x)$ is the equivalent draft defined by the ratio of sectional area $A(x)$ to the breadth $B(x)$ of the $x$-section $A(x) / B(x)$.

Then the sinkage $\zeta_{G}$ and trim angle $\theta$ of ship in irregular waves may mainly be determined by the static balance based on the Froude-Krylov force because the encounter frequency of ship to waves is relatively low.
Since the ship weight $W$ should be equal to the $z^{-}$ component of force acting on the submerged volume and the moment about the center of gravity should be zero, the sinkage $\zeta_{G}$ and trim angle $\theta$ are given by the following equations

$$
W=\int_{L} A(x)\left(\frac{\partial p}{\partial z}\right) d x, \quad \int_{L} x A(x)\left(\frac{\partial p}{\partial z}\right) d x=0
$$

Substituting Eq.(10) into Eq.(11), the integrals are decomposed as

$$
\begin{aligned}
& \int_{L} A(x)\left(\frac{\partial p}{\partial z}\right) d x \\
& =\rho g \int_{L} A(x) d x+\rho \sum_{n=1}^{N} C_{n} \omega_{n}^{2} \\
& \quad \times \cos \left[\frac{\omega_{n}^{2}}{g} \xi_{0}-\left(\omega_{n}-\frac{\omega_{n}^{2}}{g} U\right) t+\varepsilon_{n}\right] \\
& \quad \times \int_{L} \exp \left[-\frac{\omega_{n}^{2}}{g} d(x)\right] A(x) \cos \frac{\omega_{n}^{2}}{g} x d x \\
& \quad-\rho \sum_{n=1}^{N} C_{n} \omega_{n}^{2} \sin \left[\frac{\omega_{n}^{2}}{g} \xi_{0}-\left(\omega_{n}-\frac{\omega_{n}^{2}}{g} U\right) t+\varepsilon_{n}\right] \\
& \quad \times \int_{L} \exp \left[-\frac{\omega_{n}^{2}}{g} d(x)\right] A(x) \sin \frac{\omega_{n}^{2}}{g} x d x \\
& \int_{L} x A(x)\left(\frac{\partial p}{\partial z}\right) d x \\
& =\rho g \int_{L} x A(x) d x+\rho \sum_{n=1}^{N} C_{n} \omega_{n}^{2} \cos \left[\frac{\omega_{n}^{2}}{g} \xi_{0}-\left(\omega_{n}-\frac{\omega_{n}^{2}}{g} U\right) t\right. \\
& \left.\quad+\varepsilon_{n}\right] \times \int_{L} x \exp \left[-\frac{\omega_{n}^{2}}{g} d(x)\right] A(x) \cos \frac{\omega_{n}^{2}}{g} x d x \\
& \quad-\rho \sum_{n=1}^{N} C_{n} \omega_{n}^{2} \sin \left[\frac{\omega_{n}^{2}}{g} \xi_{0}-\left(\omega_{n}-\frac{\omega_{n}^{2}}{g} U\right) t+\varepsilon_{n}\right] \\
& \quad \times \int_{L} x \exp \left[-\frac{\omega_{n}^{2}}{g} d(x)\right] A(x) \sin \frac{\omega_{n}^{2}}{g} x d x
\end{aligned}
$$

Since large amplitude motions and finite amplitude waves are assumed, the sectional area $A(x)$ varies with respect to the sinkage $\zeta_{G}$, trim angle $\theta$ and wave profile $\zeta_{w}$ along the ship length. So that Eq. (11) is solved for $\zeta_{G}$ and $\theta$ by numerical integration. When the immersed sectional area $A(x)$ and the breadth $B(x)$ at the wave surface are given, the metacentric height $G M$ (wave) is obtained from the following formula

$$
G M=\frac{I}{\nabla}-B G
$$

where

$$
I=\frac{2}{3} \int_{L}\left[\frac{B(x)}{2}\right]^{3} d x, \quad \nabla=\int_{L} A(x) d x
$$

The metacentric height $G M$ (wave) in waves can be divided into two parts of the metacentric height $G M($ still $)$ in still water and the change $\triangle G M$ in waves as

$$
G M(\text { wave })=G M(\text { still })+\Delta G M
$$

Then $\triangle G M / G M$ will be written as

$$
\frac{\Delta G M}{G M}=a_{0}+\sum_{n=1}^{N} a_{n} \cos \left[\frac{\omega_{n}^{2}}{g} \xi_{0}-\left(\omega_{n}-\frac{\omega_{n}^{2}}{g} U\right) t+\varepsilon_{n}\right]
$$

where $a_{0}$ and $a_{n}$ are the coefficients given by integrating Eqs. (12) and (13) with respect to the variable $x$.

In order to consider ship rolling and capsizing of a ship in irregular following waves, it is an interesting point to evaluate the change of metacentric height which depend on the configuration of the waves en- 
countered by the ship. According to Eq. (17), it will be important to evaluate the effect of ship speed $U$ on the metacentric height because there is a great deal of difference between the wave configuration observed in a space fixed coordinate system and the resulting excitation experienced by the ship running in following waves. In Eq. (17) the coefficients $a_{0}$ to $a_{n}$ are determined by the wave configuration around the ship in space fixed coordinate system, and the wave configuration encountered by the ship running in irregular following waves depends on the ship speed $U$ and the circular frequency $\omega_{n}$ of component waves. Accordingly, Eq. (17) is the final result to evaluate the magnitude of $\triangle G M$ and the encounter frequency of ship to waves in the time domain.

Power spectrum of metacentric height

The statistical approach may be more understandable to analyze an irregular phenomena in the time domain. Let us next consider the power spectrum of metacentric height in irregular following waves. It could be possible to obtain the power spectrum $S_{G M}(\omega)$ of $\triangle G M$ from the $\triangle G M$ in the time domain if the power spectrum for irregular seas is given. Since the auto correlation function $R(\tau)$ of $\Delta G M$ is

$$
R(\tau)=\lim _{T \rightarrow \infty} \frac{1}{T} \int_{-T / 2}^{T / 2} \Delta G M(t) \Delta G M(t+\tau) d t
$$

the power spectrum $S_{G M}(\omega)$ is obtained from the Fourier transformation of $R(\tau)$ as

$$
S_{G M}(\omega)=\frac{1}{2 \pi} \int_{-\infty}^{\infty} R(\tau) \exp [-i \omega \tau] d \tau
$$

\section{Equation of Motion}

The low cycle resonance has been traditionally investigated for a ship running in regular astern seas. The equation of motion has been widely described as Mathieu's differential equation taking into account the fluctuation of metacentric height GM. However, there seems to be a lack of solid foundation for determining the practical application to the ship design. Because of the random nature of the sea, the ship motion at sea is also essentially random. The problem here is to derive a mathematical model describing low cycle resonance of the ship running in irregular astern seas composed by a number of elementary waves.

The traditional mathematical model will provide a reference frame to this problem. Therefore, the following mathematical model will be used to describe the low cycle resonance taking into account the fluctuation of metacentric height in irregular astern seas.

$$
\ddot{\phi}+2\left(\frac{2 a_{e}}{T}\right) \dot{\phi}+\left(\frac{2 \pi}{T}\right)^{2}\left[1+\frac{\Delta G M}{G M}\right] \phi=0
$$

Then $\triangle G M / G M$ will be written as

$$
\frac{\Delta G M}{G M}=a_{0}+\sum_{n=1}^{N} a_{n} \cos \left[\frac{\omega_{n}^{2}}{g} \xi_{0}-\left(\omega_{n}-\frac{\omega_{n}^{2}}{g} U\right) t+\varepsilon_{n}\right]
$$

where $T$ is natural rolling period and $a_{e}$ effective extinction coefficient.

Substituting the Eq. (21) into Eq. (20), the stable and unstable regions can be obtained from the solution of Eq. (20). On the other hand, assuming the significant wave height $H_{1 / 3}$ and average wave period $T_{01}$ corresponding to irregular waves, $\triangle G M / G M$ can be written as

$$
\frac{\Delta G M}{G M}=a_{0}+a_{1 / 3} \cos \left[\frac{\omega_{01}^{2}}{g} \xi_{0}-\left(\omega_{01}-\frac{\omega_{01}^{2}}{g} U\right) t\right]
$$

here $a_{0}$ is constant component, $a_{1 / 3}$ the significant fluctuation of $\triangle G M / G M$ corresponding to $H_{1 / 3}$ and $\omega_{01}$ is wave frequency corresponding to average wave period $T_{01}$.

So that, substituting Eq. (22) into Eq. (20), it will be possible to obtain an another solution of Eq. (20) with respect to regular seas.

For discussion it is possible to make comparison between the solutions described by two kinds of $\triangle G M / G M$ fluctuation. It therefore seems appropriate to develop a simplified method in this aspect.

\section{Examples of Numerical Computation}

Several examples of numerical computation are computed for two types of $15000 \mathrm{GT}$ container ship and purse seiner of $135 \mathrm{GT}$ with body plan as shown in Figs. 2 and 3 respectively. In addition the principal dimensions of both ships are shown in Tables 1 and 2 for which free running model tests were previously conducted at National Research Institute of Fisheries Engineering in Japan to investigate the dangerous situation of ships in astern seas ${ }^{5), 6)}$.

\section{$\triangle G M$ of container ship}

The change $\triangle G M$ of metacentric height was calculated in case of $G M=0.15 \mathrm{~m}$ which satisfies the IMO resolutions A 167 and A 562. Fig. 4 indicates the time histories of wave profiles $\zeta_{w}$ encountered at the midship and the change $\triangle G M$ of metacentric height in cases of $F_{n}=0,0.15$ and 0.27 . Here the $\zeta_{w}$ is obtained from Eq. ( 8 ) using ITTC spectrum (1978) at $H_{1 / 3}=13.26 \mathrm{~m}$ and $T_{01}=10.92 \mathrm{sec}$. The $\triangle G M$ is obtained from Eq. (17). When the $F_{n}$ is higher, the periods of $\zeta_{w}$ and $\Delta G M$ become longer.

Fig. 5 indicates the power spectra of $\zeta_{w}$ and $\Delta G M$ which are calculated from Eq. (19) in cases of $F_{n}=0$, 0.15 and 0.27 . When the $F_{n}$ is higher, the power spectra have a spike-like peak which is the same form as the power spectrum transformed into the encounter wave spectrum by means of the following relation

$$
S_{w}\left(\omega_{e}\right)=\frac{S_{w}(\omega)}{|1-2 \omega U / g|}
$$

\section{$\triangle G M$ of purse seiner}

In the same way, Figs. 6 , and 7 indicate the time histories of $\zeta_{w}$ and $\triangle G M$, and the power spectra of $\zeta_{w}$ and $\Delta G M$ respectively. The $\zeta_{w}$ is obtained from Eq. ( 8 ) using ITTC spectrum (1978) at $H_{1 / 3}=4.08 \mathrm{~m}$ and $T_{01}=$ $6.20 \mathrm{sec}$. Although the $\triangle G M$ of container ship is different from that of purse seiner as shown in Figs. 4, and 6 , this difference is seen to be related to the difference of ship hull form. The metacentric height at 

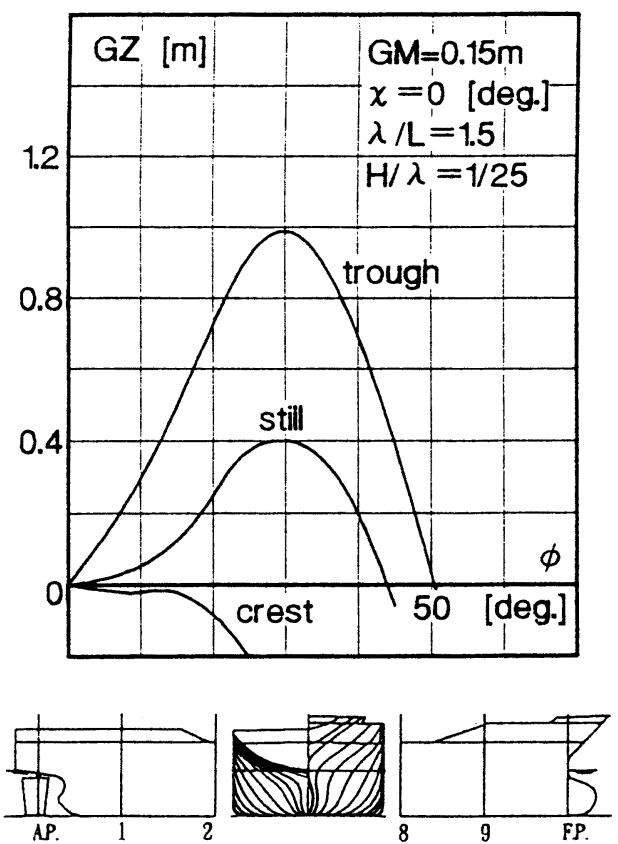

Fig. 2 Body plan and $G Z$ curve of container ship
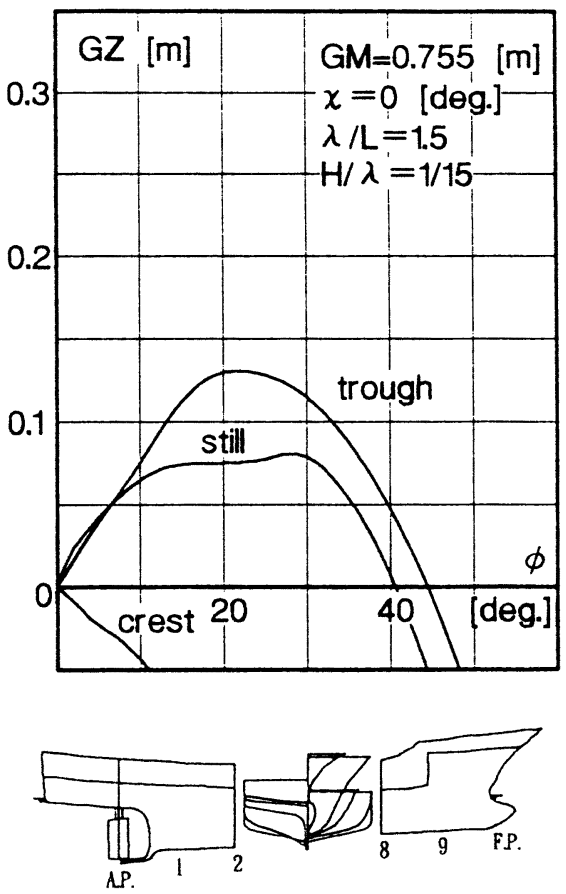

Fig. 3 Body plan and $G Z$ curve of purse seiner

the trough amidships is remarkably larger than that in still water if the ship has a hard flare at the bow and stern, and a high freeboard. In this case, the freeboard of container ship and purse seiner are very high and low
Table 1 Principal dimensions of container ship

\begin{tabular}{|l|l|c|r|}
\hline \hline \multicolumn{2}{|c|}{ Items } & Ship & Model \\
\hline Length & $\mathrm{L}(\mathrm{m})$ & 150.0 & 2.5 \\
Breadth & $\mathrm{B}(\mathrm{m})$ & 27.2 & 0.453 \\
Depth & $\mathrm{D}(\mathrm{m})$ & 13.5 & 0.225 \\
Draft & $d_{f}(\mathrm{~m})$ & 8.50 & 0.142 \\
& $d_{a}(\mathrm{~m})$ & 8.50 & 0.142 \\
Block Coef. & $C_{b}$ & 0.667 & 0.667 \\
Model Scale & - & - & $1 / 60$ \\
\hline \hline
\end{tabular}

Table 2 Principal dimensions of purse seiner

\begin{tabular}{|l|l|c|r|}
\hline \hline \multicolumn{2}{|c|}{ Items } & Ship & Model \\
\hline Length & $\mathrm{L}(\mathrm{m})$ & 34.5 & 2.3 \\
Breadth & $\mathrm{B}(\mathrm{m})$ & 7.6 & 0.507 \\
Depth & $\mathrm{D}(\mathrm{m})$ & 3.07 & 0.205 \\
Draft & $d_{f}(\mathrm{~m})$ & 2.84 & 0.189 \\
& $d_{a}(\mathrm{~m})$ & 3.14 & 0.209 \\
Block Coef. & $C_{b}$ & 0.652 & 0.652 \\
Model Scale & - & - & $1 / 15$ \\
\hline \hline
\end{tabular}

respectively. Therefore, the purse seiner has the possibility that the sea surface is partially beyond the upper deck.

Discussion on metacentric height in longitudinal waves

Let us here consider the reason why $\Delta G M$ of purse seiner is different from that of container ship. As well known, the metacentric height $G M$ consists of the moment of inertia $I$ of entire waterplane about the ship's centerline, the displacement $\nabla$ of ship and the distance $B G$ between the center of buoyancy and gravity designated as Eq. (14). Since $I$ in still water is given by integrating the half breadth $y$ as

$$
I=\frac{2}{3} \int_{-\frac{L}{2}}^{\frac{L}{2}} y^{3} d x
$$

the small change $\Delta I$ of $I$ in a longitudinal wave is approximately described by the small change $\Delta y$ of $y$ as

$$
\begin{aligned}
I+\Delta I & =\frac{2}{3} \int_{-\frac{L}{2}}^{\frac{L}{2}}(y+\Delta y)^{3} d x \\
& \simeq \frac{2}{3} \int_{-\frac{L}{2}}^{\frac{L}{2}}\left[y^{3}+3 y^{2} \Delta y+3 y \Delta y^{2}\right] d x
\end{aligned}
$$

$\Delta I$ is

$$
\Delta I=2 \int_{-\frac{L}{2}}^{\frac{L}{2}}\left(y^{2} \Delta y+y \Delta y^{2}\right) d x
$$

The first term indicates the effect of increase and decrease of half breadth at wave trough and crest amidships, and the second term has always positive constant without respect to the relative position of ship to a wave because of $\Delta y^{2}$. This fact has been already pointed out by Kerwin ${ }^{2)}$ in 1955 . When the container ship is running in regular seas, $B M$ varies with respect to the relative position $\xi_{G} / \lambda$ of ship to a wave and the sea surface is under the upper deck as shown in the left 

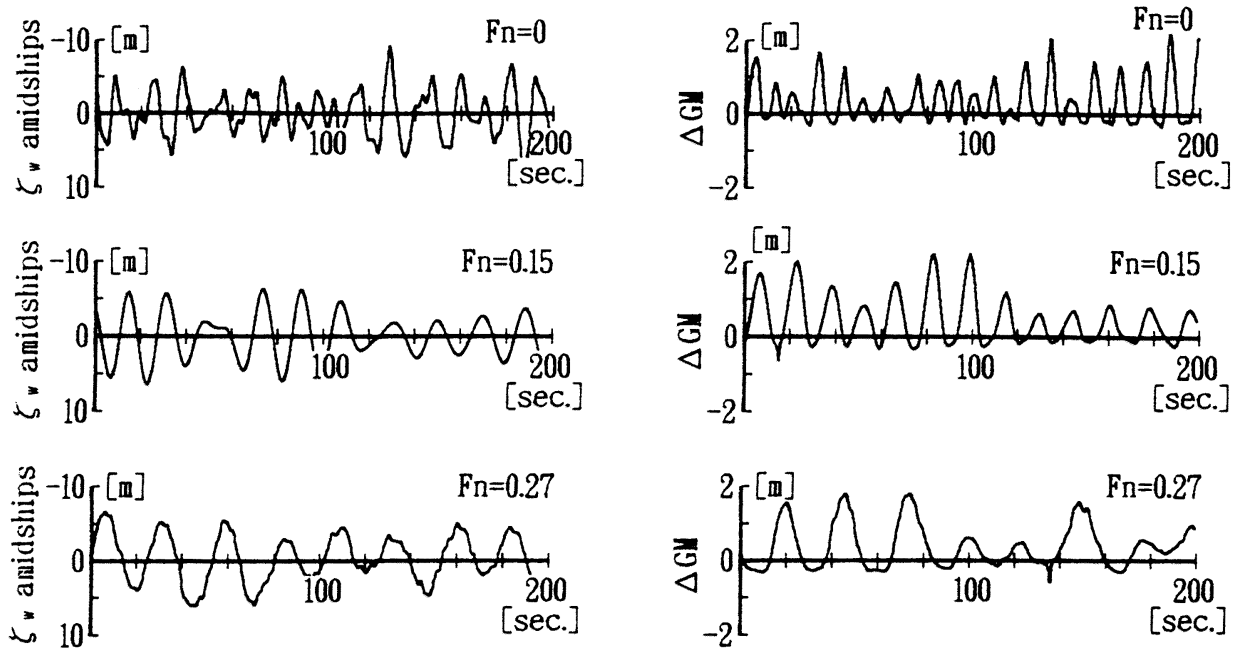

Fig. 4 Time histories of encounter wave and the change of metacentric height for container ship

$\mathrm{H}_{1 / 3}=13.26 \mathrm{~m} \quad \mathrm{~T}_{01}=10.92 \mathrm{sec}$.

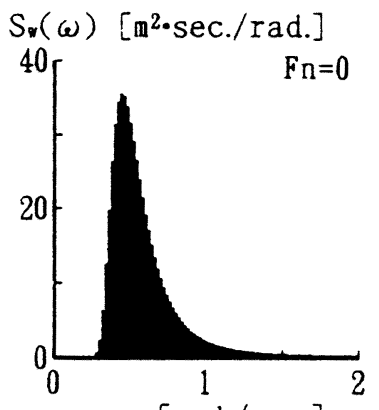

$\mathrm{S}_{*}(\omega)\left[\mathrm{m}^{2} \cdot \mathrm{sec} . / \mathrm{rad}.\right]$

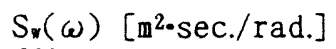

$\omega[\mathrm{rad} . / \mathrm{sec}$.
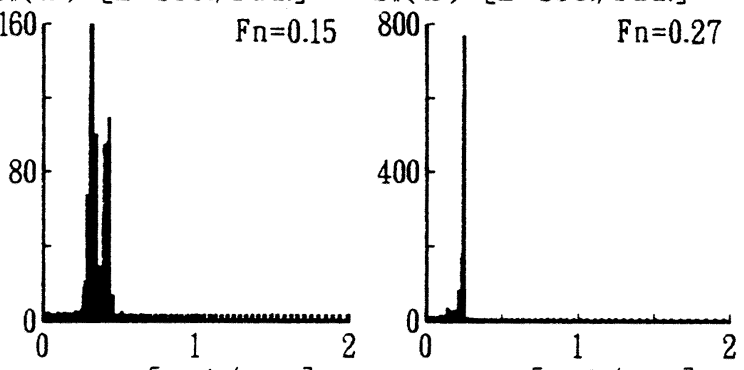

$\omega$ [rad./sec.]

$\omega[\mathrm{rad} . / \mathrm{sec}$.

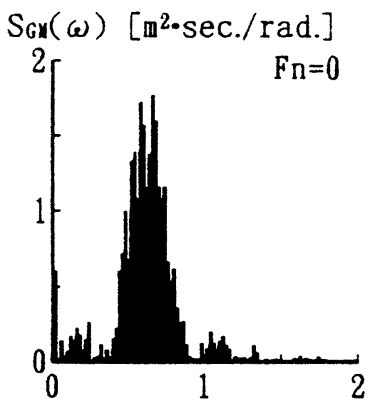

$\omega$ [rad./sec.]
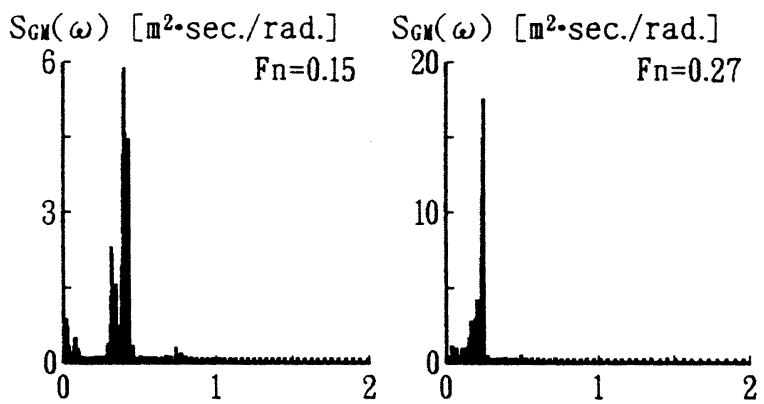

Fig. 5 Power spectra of waves and metacentric height for container ship

side of Fig. 8. According to the brief analysis mentioned above, $G M$ of the container ship running in longitudinal waves increases in the average.

For the purse seiner running in longitudinal seas, the upper deck is partially submerged because of small freeboard. In this situation, $I$ decreases by the submerged area of upper deck. Namely, the partially submerged area of upper deck makes no contribution to $I$. The sea surface is partially beyond the upper deck of purse seiner running in regular seas as shown in the right side 

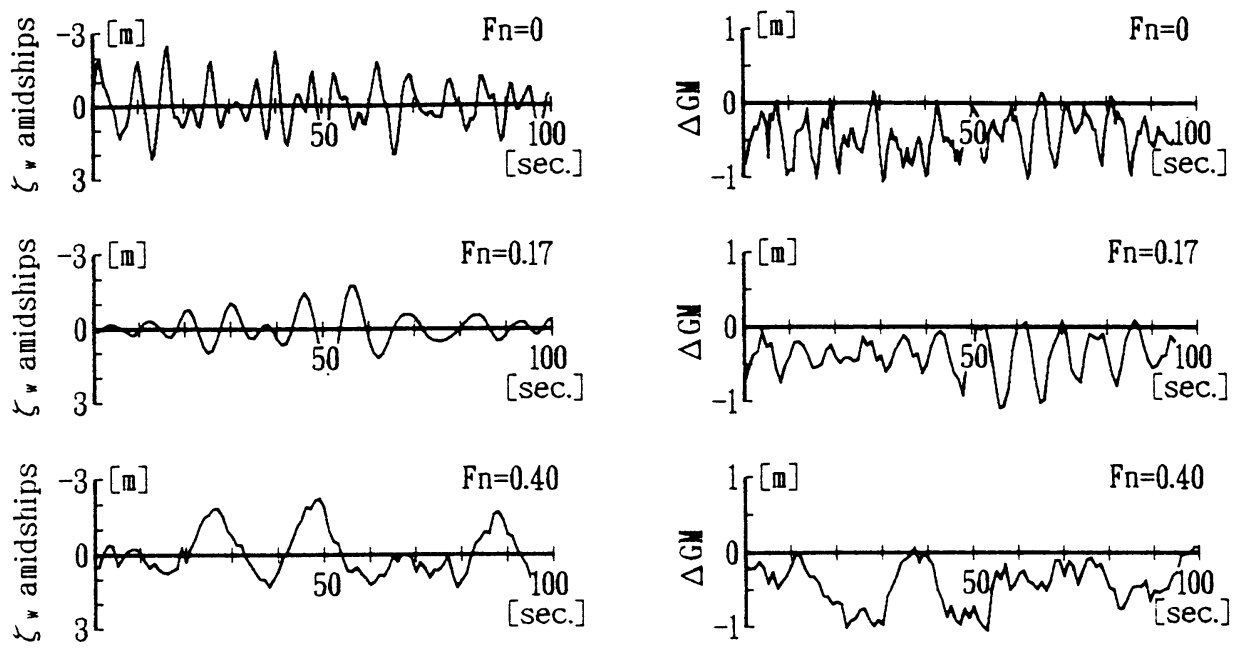

Fig. 6 Time histories of encounter wave and the change of metacentric height for purse seiner

$\mathrm{H}_{1 / 3}=4.08 \mathrm{~m} \quad \mathrm{~T}_{01}=6.20 \mathrm{sec}$.

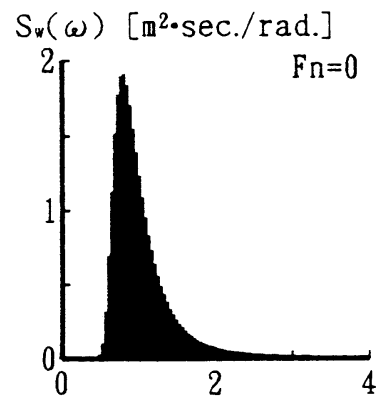

$\omega[\mathrm{rad} . / \mathrm{sec}$.

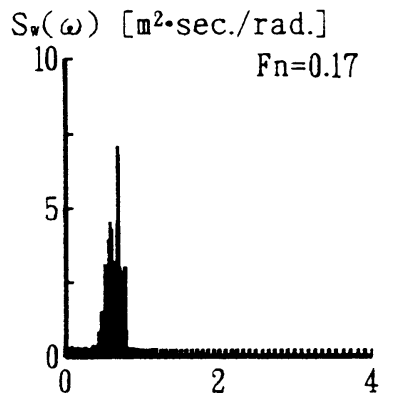

$\omega$ [rad./sec.]

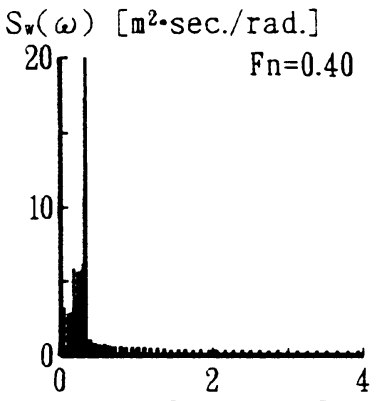

$\omega[\mathrm{rad} . / \mathrm{sec}$.

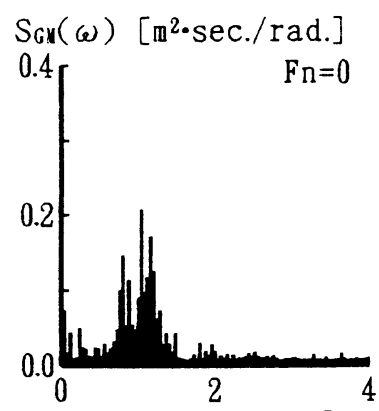

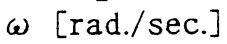

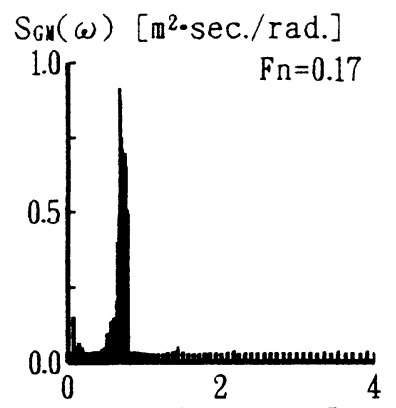

$\omega[\mathrm{rad} . / \mathrm{sec}$.

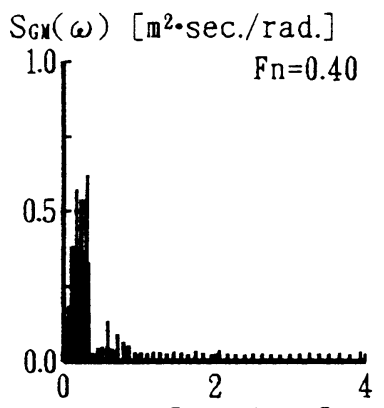

$\omega$ [rad./sec.]

Fig. 7 Power spectra of waves and metacentric height for purse seiner

of Fig. 8. That is the reason why $G M$ of purse seiner running in longitudinal waves decreases in the average. Low Cycle Resonance for container ship

The unstable region of low cycle resonance is given by the solution of Eq. (20) which can be obtained from the step-by-step approximation method in the time domain. The computations were carried out in the time interval $500 \mathrm{sec}$. Since Eq. (20) is the Mathieu's equation with the linear righting moment, the rolling angle would be developed until very large angle over the 
Container ship
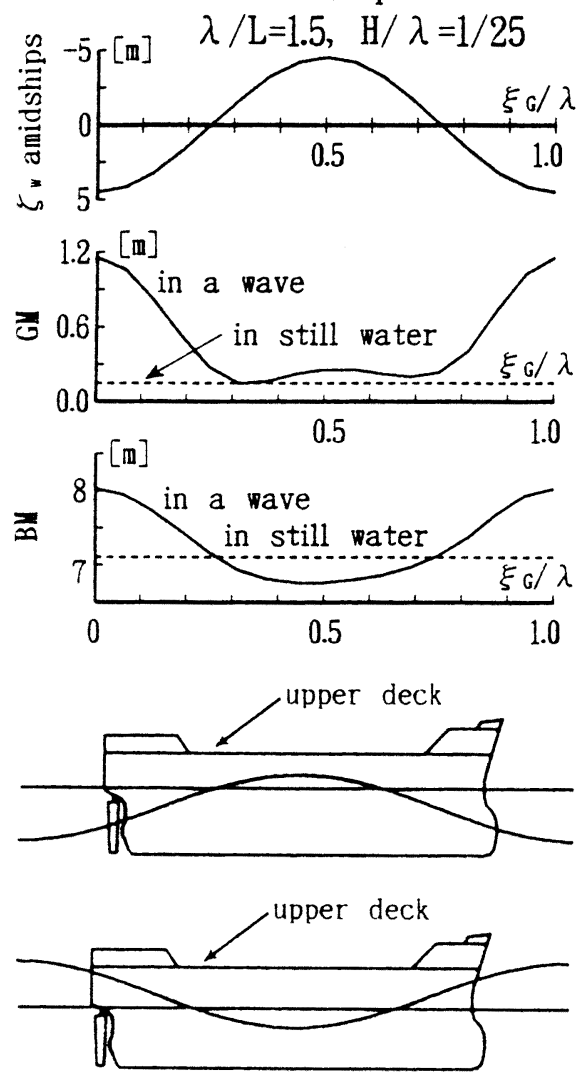

Purse seiner
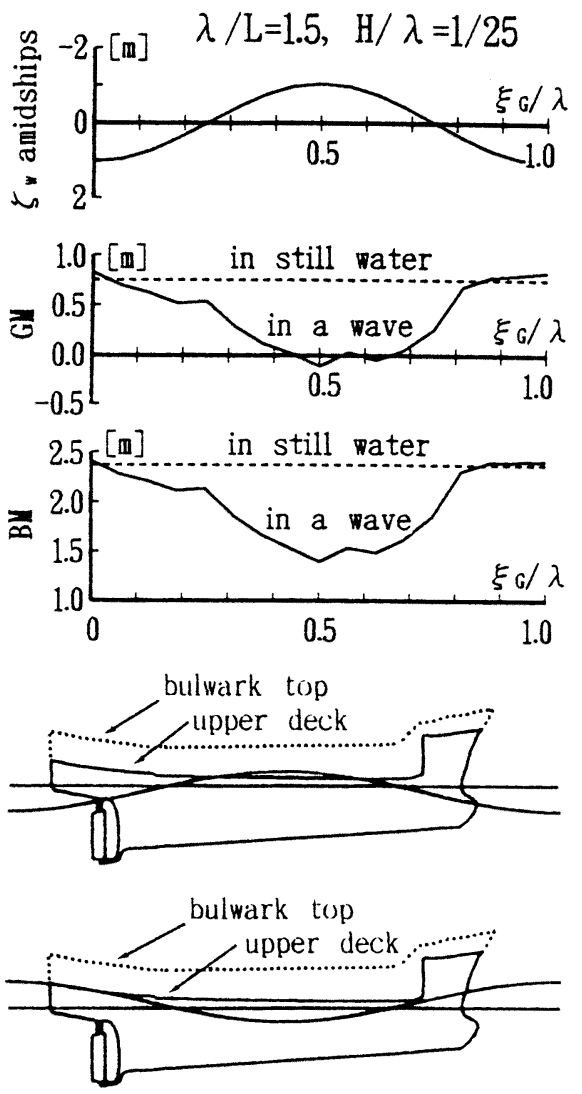

Fig. 8 Variations of $G M$ and $B M$ with respect to the relative position of ship to a wave

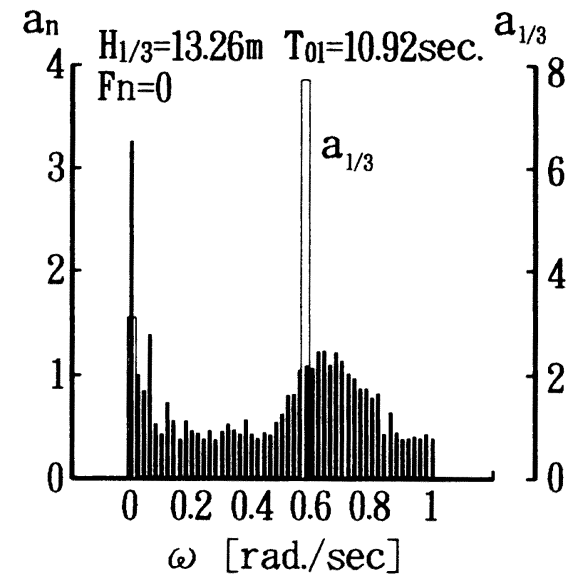

Fig. 9 The coefficient $a_{n}$ and $a_{1 / 3}$ for container ship

vanishing angle of $G Z$ curve or damped out at the specific condition. For specifying stable and unstable regions, an assumption is considered to be capsized when the rolling angle reaches the vanishing angle of
$G Z$ curve. It is necessary for solving Eq. (20) to evaluate $a_{0}$ and $a_{n}$ in Eq. (21). Here $a_{0}$ is the constant component of metacentric height in the time domain and $a_{n}$ can be evaluated from the power spectrum of metacentric height $S_{G M}\left(\omega_{n}\right)$ as

$$
a_{n}=\frac{\sqrt{2 S_{G M}\left(\omega_{n}\right) \Delta \omega}}{G M(\text { still })}
$$

Fig. 9 indicates the frequency component of metacentric height for the container ship at $F_{n}=0$. Fig. 10 shows unstable regions of the container ship running in irregular astern seas. In this figure, the wave height is equal to the significant wave height $H_{1 / 3}$ in Eq. ( 3 ) and $\lambda$ is given by

$$
\lambda=\frac{g T_{01}^{2}}{2 \pi}
$$

The Froude-number varies from $F_{n}=0$ to $F_{n}=0.4$ corresponding to 30 knots. The wave height to length ratio varies from $H / \lambda=0$ to $H / \lambda=1 / 12$ corresponding to significant wave height $H_{1 / 3}$ in irregular seas, and the wave to the ship length ratio are $\lambda / L=1.0,1.24$, and 1.5.

For reference, it may be interesting to compare the unstable region in irregular seas with that in regular seas. Fig. 11 indicates unstable regions of the container 

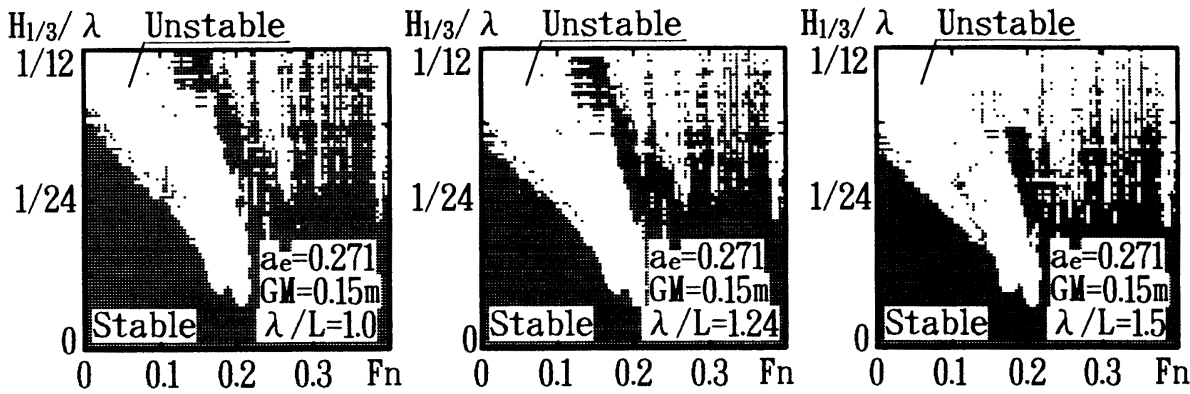

Fig. 10 Low cycle resonance for container ship in irregular astern seas
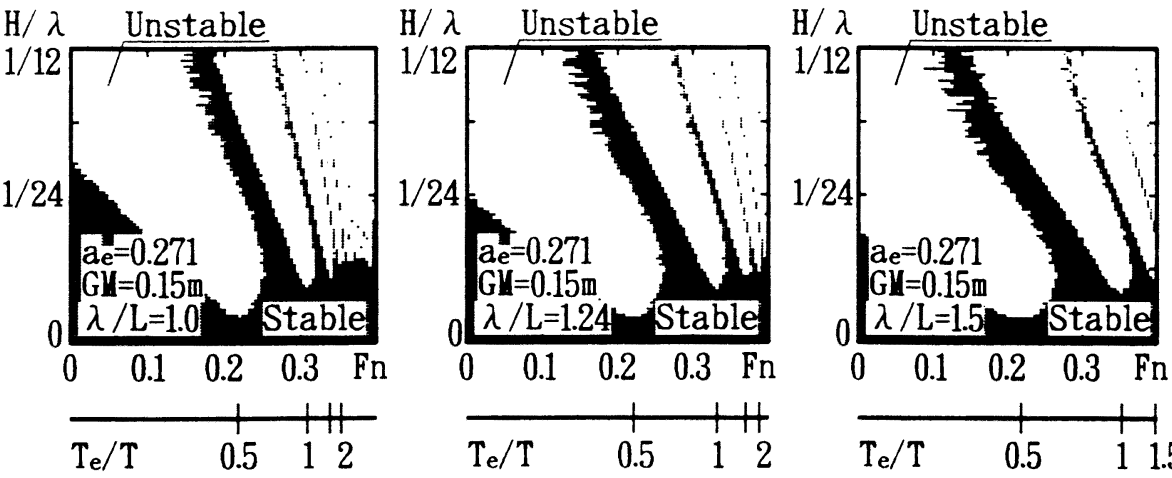

Fig. 11 Low cycle resonance for container ship in regular astern seas

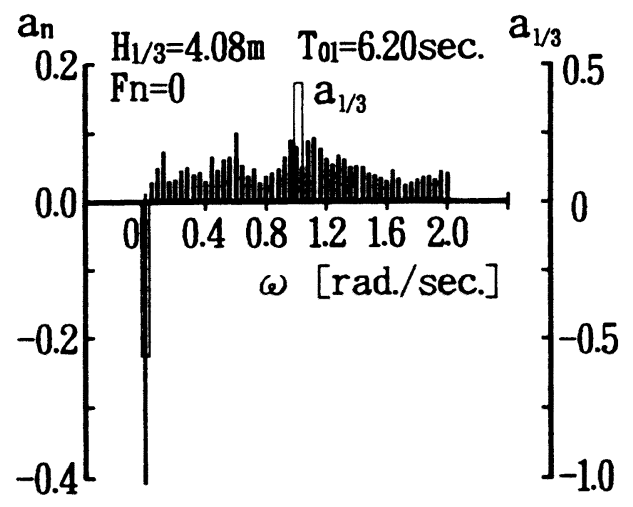

Fig. 12 The coefficient $a_{n}$ and $a_{1 / 3}$ for purse seiner

ship running in regular astern seas. In this figure, the wave height to length ratio $H / \lambda$ and the wave to ship length ratio $\lambda / L$ of regular seas are equal to the significant wave height to length ratio $H_{1 / 3} / \lambda$ and the significant wave to ship length ratio $\lambda / L$ of irregular seas. The configuration of stable and unstable regions is fairly similar but the size of them is different. Namely, the unstable region of the ship running in regular seas is wider than that in irregular seas. Since the rolling motion in longitudinal waves is parametrically excited in a harmonic process, the possibility leading to unstable rolling might be larger for the ship running in regular waves.

Low Cycle Resonance for purse seiner

In the same way, Fig. 12 indicates the frequency component of metacentric height for the purse seiner at $F_{n}=0$. The constant coefficient $a_{0}$ of purse seiner is considered to have a negative value because of small freeboard compared with that of the container ship. Fig. 13 shows unstable regions of the purse seiner running in irregular astern seas. Fig. 14 shows unstable regions of the purse seiner running in regular astern seas. The unstable region of the purse seiner is narrower than that of the container ship. That would be the reason why the natural rolling period of the purse seiner is too small to satisfy the critical condition of low cycle resonance $T_{e} / T=1 / 2$.

\section{Conclusions}

When a ship is running in irregular astern seas, the power spectrum of the encounter frequency of ship become narrower than the power spectrum of irregular seas. Takaishi ${ }^{4}$ has already pointed out this phenomena by the method to transform the power spectrum of irregular seas into the power spectrum of encounter frequency of ship running in irregular astern seas. In this paper, an another approach to this phenomena has 

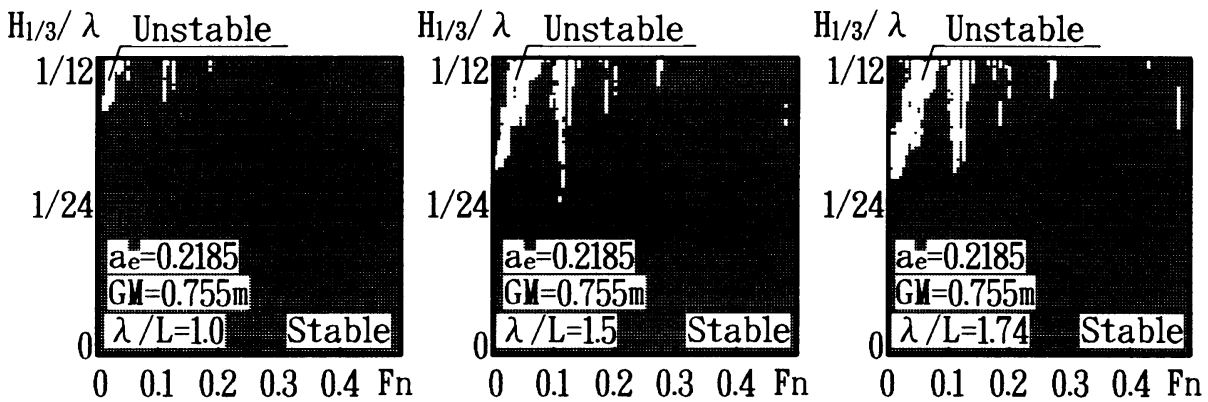

Fig. 13 Low cycle resonance for purse seiner in irregular astern seas
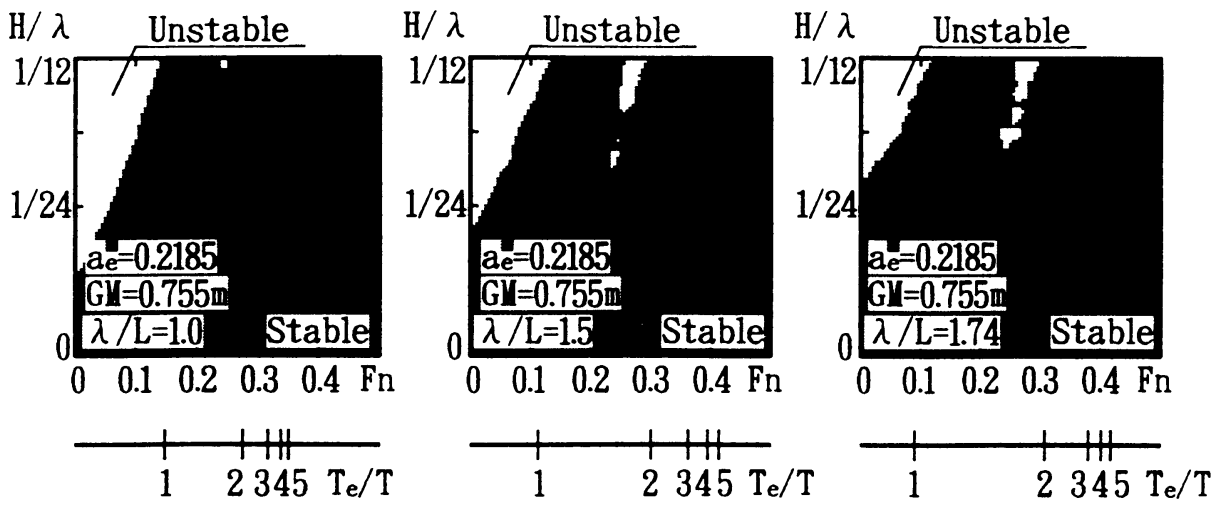

Fig. 14 Low cycle resonance for purse seiner in regular astern seas

been tried to evaluate the potential velocity of irregular seas. The main results obtained from the new method are summarized as follows.
(1) The metacentric height $G M$ of ships in irregular astern seas has been investigated as a random process in the time domain.
(2) The power spectrum of metacentric height has been evaluated for a container ship and a purse seiner running in irregular astern seas.
(3) The power spectrum of $G M$ fluctuation has a narrow frequency band for the ship running at high speed.
(4) An equation of motion is derived for the low cycle resonance of ship running in irregular astern seas.
(5) The low cycle resonance has been investigated as a random process by means of numerical compu- tation.

This study was carried out under the panel RR 24 of Shipbuilding Research Association of Japan. The authors wish to express their gratitude to members of the RR 24, chaired by Prof. Fujino for productive discussions.

\section{References}

1) Grim, O.: Rollschwingungen, Stabilitat und Sicherheit im Seegang, Schiffstechnik, Vol. 1(1952), pp. 10-21.

2) Kerwin, J. E. : Notes on Rolling in Longitudinal Waves, International Shipbuilding Progress, Vol. 2, No. 16(1955), pp. 597-614.

3) Paulling, J.R.: The Transverse Stability of a Ship in a Longitudinal Seaway, Journal of Ship Research, SNAME, Vol. 4, No. 4(1961), pp. 37-49.

4) Takaishi, Y.: Consideration on the Dangerous Situations Leading to Capsize of Ships in Waves, Proceedings of the Second International Conference on Stability of Ships and Ocean Vehicles, Tokyo, (1982), pp. 243-253.

5) Umeda, N., Hamamoto, M., Takaishi, Y., Chiba, H., Matsuda, A., Sera, W., Suzuki, S., Spyrou, K., Watanabe, K. : Model Experiments of Ship Capsize in Astern Seas, Journal of the Society of Naval Architects of Japan, Vol. 177 (1995), pp. 207-217.

6) Hamamoto, M., Umeda, N., Matsuda, A., Sera, W. : Analyses on Low Cycle Resonance of Ship in Astern Seas, Journal of the Society of Naval Architects of Japan, Vol. 177 (1995), pp. 197-206. 